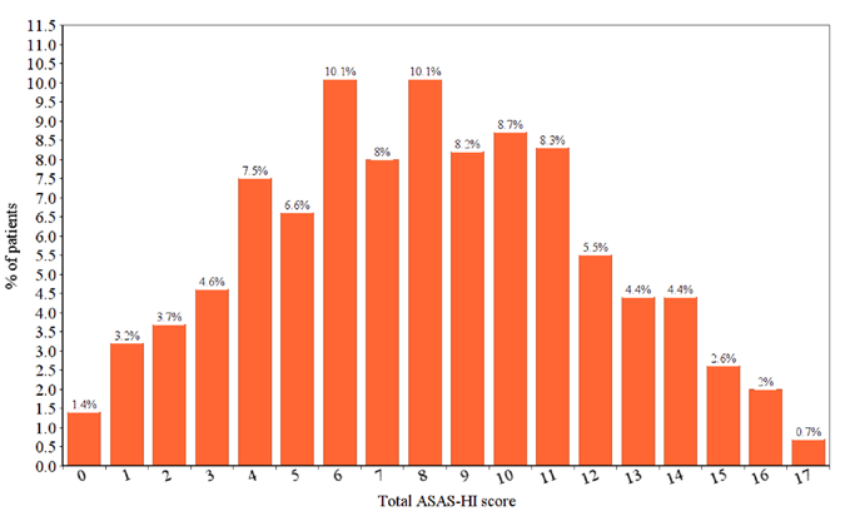

Figure 1. Distribution of the result of ASAS-HI scores $(\mathrm{N}=587)$

Conclusion: One out of five patients with axSpA reported poor health and functioning according to the ASAS-HI, and almost half of patients reported worsening self-perceived health status during the first wave of the COVID-19 pandemic.

Keywords: COVID-19, axial spondyloarthritis, ASAS-HI, health

Disclosure of Interests: Diego Benavent Grant/research support from: Abbvie, Novartis and Roche, Marco Garrido-Cumbrera: None declared., Chamaida Plasencia Grant/research support from: Pfizer, Sanofi, Novartis, Roche and Lilly, Laura Christen Employee of: Novartis Pharma AG, Helena Marzo-Ortega Grant/research support from: Abbvie, Celgene, Janssen, Elli-Lilly, Novartis, Pfizer, UCB and Takeda Pharmaceutical Company, José Correa-Fernández: None declared., Pedro Plazuelo-Ramos: None declared., Dale Webb: None declared., Victoria Navarro-Compán Grant/research support from: Abbvie, BMS, Lilly, MSD, Novartis, Pfizer, Roche, UCB

DOI: 10.1136/annrheumdis-2021-eular.2153

\section{AB0501 CORRELATION BETWEEN AXIAL AND PERIPHERAL ENTHESIS IN SPONDYLARTHRITIS}

H. Ferjani ${ }^{1}$, M. Yasmine $^{1}$, K. Maatallah ${ }^{1}$, E. Labbene ${ }^{2}$, H. Riahi ${ }^{2}$, D. Kaffel ${ }^{1}$, M. Bouaziz ${ }^{2}$, W. Hamdi'. ${ }^{1}$ Kassab Institute of Orthopedics, Rheumatology, Tunis, Tunisia; ${ }^{2}$ Kassab Institute of orthopedics, Radiology, Tunis, Tunisia

Background: Enthesitis is the clinical hallmark of spondylarthritis. It refers to the inflammation of joint attach in the bone. Several sites enthesitis may be affected, and a wide variety of scoring systems were available.

Objectives: We aimed to determine the prevalence of axial enthesitis in the anterior chest wall (ACW), and its correlation with peripheral sites especially, the Achilles tendon (AT).

Methods: We conducted a prospective study including patients with SpA according to the ASAS criteria. Sociodemographic data, as well as disease characteristics, were recorded. The Maastricht Ankylosing Spondylitis Enthesitis Score (MASES) was used to assess clinical entheses (first and seventh costochondral joints, posterior superior iliac spine, anterior superior iliac spine, iliac crest, and Achilles tendon insertion). The presence of enthesitis on the US was then assessed in the right and left sternoclavicular (SCJ), manubriosternal (MSJ) joints, as well as in the AT, using Esaote My Lab 50.

Results: The study included 47 patients with SpA: axial $(n=26)$, axial and peripheral $(n=21)$. There was a female predominance (sex ratio: 0.2$)$. The mean age was 42.2 years \pm 12.6 [11-70]. The age of onset of the disease was $<40$ years in $59.6 \%$ of cases. Tenderness in entheseal sites was found in $63.8 \%$ of patients, especially in the plantar fascia and AT $(32.7 \%, 6 \%$, respectively). The mean MASES score was 2.9 [0-13]. Clinical ACW involvement (29.1\%) was at follows: 1st right chondro-sternal joint (CSJ) (19.1\%), 1st left CSJ (25.5\%), 7th right CSJ $(27.7 \%)$ and 7 th left CSJ $(31.9 \%)$.US involvement of the ACW was $14.3 \%$. Enthesitis of the AT was found in $70 \%$ of cases on US examination. ACW US involvement was correlated neither to the BMI nor to MASES score $(p=0.16$, $\mathrm{p}=0.6$ respectively). Similarly, there was no correlation between the presence of US ACW enthesitis and clinical nor the US AT enthesitis $(p=0.09, p=0.209$, respectively).

Conclusion: Our study showed that ACW enthesitis is frequent in SpA, especially by US screening. This axial enthesitis, don't necessarily reflect a simultaneous clinical or US involvement of the peripheral entheses. Further studies are needed to characterize this subtype of SpA.

REFERENCES:

[1] Verhoeven F, Guillot X, Godfrin-Valnet M, Prati C, Wendling D. Ultrasonographic evaluation of the anterior chest wall in spondyloarthritis: a prospective and controlled study. J Rheumatol. 2015;42(1):87-92
Disclosure of Interests: None declared.

DOI: 10.1136/annrheumdis-2021-eular.2229

\section{AB0502 HEALTH-RELATED QUALITY OF LIFE MEASURES IN SPONDYLOARTHROPATY PATIENTS UNDER BIOLOGICAL THERAPIES IN REAL LIFE}

E. Grau García ${ }^{1}$, M. De la Rubia Navarro ${ }^{1}$, C. Pávez Perales ${ }^{1}$, S. Leal Rodriguez $^{1}$, C. Riesco Barcena ${ }^{1}$, A. V. Huaylla Quispe ${ }^{1}$, E. Vicens Bernabeu ${ }^{1}$, R. Negueroles Albuixech ${ }^{1}$, J. Ivorra Cortés ${ }^{1}$, F. M. Ortiz Sanjuan ${ }^{1}$, I. Martínez Cordellat $^{1}$, I. Chalmeta Verdejo ${ }^{1}$, J. J. Fragío Gil ${ }^{1}$, L. Gonzalez Puig ${ }^{1}$, J. E. Oller Rodríguez ${ }^{1}$, C. Alcañiz Escandell, I. Cánovas Olmos ${ }^{1}$, C. Nájera Herranz ${ }^{1}$, A. J. Cañada Martinez ${ }^{2}$, J. A. Román Ivorra ${ }^{1} .{ }^{1} \mathrm{HUP} \mathrm{La} \mathrm{Fe}$, Rheumatology Department, Valencia, Spain; ${ }^{2} I I S$ La Fe, Biostatistics Unit, Valencia, Spain

Background: Spondyloarthropathy patients have reduced health-related quality of life (HRQL) compared to general population. Biological treatmen strategies in real life aim to reduce patients' symptoms and different HRQL parameters would share the same behavior as patients' symptoms and disease activity.

Objectives: We aim to assess the differences in HRQL reported by spondyloarthropathy patients during the first six months of biological therapy according to the treatment effectiveness.

Methods: We performed a prospective observational study of six months of follow-up in spondyloarthropathy patients who are newly on biological therapy. A basal visit and 1, 3 and 6 months follow-up visits were conducted. We analyzed changes during follow-up in the HRQL parameters reported by patients through AsqoL and ASAS-health-index questionnaires. Moreover we measured functional disability through $\mathrm{HAQ}$ and BASFI index, disease activity by BASDAI, ASDAS-CRP and ASDAS-ESR index.

Statistical analyses were achieved using $\mathrm{R}$ software, through multivariate linear regression models for continuous data and Bayesian mixed ordinal regression models with monotonic effect for ordinal data. The corresponding odd ratios (OR) were calculated with their confidence intervals ( $\mathrm{Cl} 95 \%)$.

Results: We included 53 patients $(71.77 \%$ male), the $73.58 \%$ diagnosed with ankylosing spondylitis (AS) and the $26.42 \%$ with axial spondyloarthritis. Mean age at the beginning of treatment was 48.74 (11.21) years, mean age at diagnosis was 41.57 (11.97) and mean disease evolution was 7.19 (9.24) years. $60.42 \%$ of them exhibited HLAb27 positivity.

34 patients started biological therapy with TNF- $\alpha$ inhibitors and 19 with IL-17 inhibitors. The $81.13 \%$ of patients were under monotherapy, and the other $18.87 \%$ was treated with DMARDs. The $77.36 \%$ of the total number of patients was on the biological therapy at 6 months of follow-up, while the $22.64 \%$ discontinued at 6 months of follow-up ( 9 due to inefficacy and 3 due to adverse effects).

42 patients completed the follow-up at 6 months, and 3 patients achieved unti visit 3 due to treatment failure. In 1 case visit 1 and in 7 cases visit 3 could not be performed due to COVID19 pandemic situation.

We observed a significant correlation among AsqoL and ASAS-hi values with disease activity indexes (BASDAI, ASDAS-CRP, ASDAS-ESR) and functiona disability (HAQ, BASFI). The statistical analyses showed a significant association where AsqoL and ASAS-hi values are significantly decreased in treatment failures compared to the successful treatment (, and in patients with previous biological therapy compared to naïve patients. No effect of years of disease evolution and the type of biological treatment in the AsqoL and ASAS-hi values was observed. (See Table 1) These results were consistent with the significant association found among the disease activity and functional disability with the biological therapy efficacy and the previous biological treatment.

\section{Table 1.}

\begin{tabular}{llllll}
\hline $\begin{array}{l}\text { Comparison with } \\
\text { effectiveness of } \\
\text { biological therapy }\end{array}$ & $\begin{array}{l}\text { Odds } \\
\text { Ratio } \\
(\mathrm{OR})\end{array}$ & $95 \% \mathrm{Cl}$ & $\begin{array}{l}\text { Comparison with } \\
\text { previous biological } \\
\text { therapy }\end{array}$ & $\begin{array}{l}\text { Odds } \\
\text { Ratio } \\
(\mathrm{OR})\end{array}$ & $95 \% \mathrm{Cl}$ \\
\hline AsqoL & 1.502 & $1.123-2.033$ & AsqoL & 10.704 & $1.232-108.504$ \\
ASAS-HI & 1.56 & $1.184-2.078$ & ASAS-HI & 11.553 & $1.299-108.974$ \\
BASDAI & 1.5 & $1.199-2.04$ & BASDAl & 11.96 & $1.823-86.901$ \\
BASFI & 1.348 & $1.036-1.76$ & BASFI & 18.37 & $2.15-176.988$ \\
ASDAS-CRP & 1.538 & $1.176-2.036$ & ASDAS-CRP & 8.869 & $2.001-42.272$ \\
ASDAS-ESR & 1.944 & $1.166-3.384$ & ASDAS-ESR & 44.621 & $2.886-1077.816$ \\
HAQ & 1.524 & $1.154-2.027$ & HAQ & 24.111 & $1.779-371.742$ \\
\hline
\end{tabular}

Conclusion: The AsqoL and ASAS-hi questionnaire results are correlated with disease activity and functional disability and showed the same behaviour as these parameters, being also associated to the biological therapy efficacy as 